\title{
Aceitação sensorial e composição centesimal da carne de ovelhas abatidas em diferentes estágios fisiológicos
}

\author{
[Sensorial acceptance and centesimal composition in the meat of ewes slaughtered in \\ different physiological stages] \\ R.S.B. Pinheiro ${ }^{1}$, A.M. Jorge ${ }^{2}$, H.B.A. Souza ${ }^{3}$ \\ ${ }^{1}$ Universidade Estadual Paulista "Júlio de Mesquita Filho" - FEIS - Ilha Solteira, SP \\ ${ }^{2}$ Universidade Estadual Paulista "Júlio de Mesquita Filho" - FMVZ - Botucatu, SP \\ ${ }^{3}$ Universidade Estadual Paulista "Júlio de Mesquita Filho" - FCAV, Jaboticabal, SP
}

\begin{abstract}
RESUMO
Estudaram-se a composição centesimal do músculo Longissimus lumborum e a aceitação sensorial do músculo Longissimus thoracis, provenientes de ovelhas de descarte da raça Santa Inês, abatidas em distintos estágios fisiológicos. Foram utilizadas 21 ovelhas, distribuídas nos seguintes grupos: $\mathrm{OL}=$ ovelhas que permaneceram por 60 dias em lactação com seus respectivos cordeiros e que foram abatidas um dia após o desmame deles; OSC = ovelhas que permaneceram por 60 dias em lactação com seus respectivos cordeiros e mais um período aproximado de 30 dias sem os cordeiros e que, posteriormente, foram abatidas; e ONP = ovelhas que não pariram durante o ano. Os teores de proteína e de cinzas da carne ovina foram semelhantes entre os grupos experimentais, e os valores de umidade e de gordura da carne diferiram entre os grupos. Não houve diferença significativa na aceitação sensorial da carne, segundo os grupos. Concluiu-se que o abate de ovelhas de descarte em diferentes estágios fisiológicos promove alteração na composição centesimal, quanto ao teor de gordura e de umidade da carne, e que não há diferença da aceitação sensorial da carne, de acordo com os grupos experimentais.
\end{abstract}

Palavras-chave: ovino, consumidor, qualidade da carne

\begin{abstract}
The objective of this research was to know the centesimal composition of the Longissimus lumborum muscle and the sensorial quality of the Longissimus thoracis muscle, proceeding from Santa Inês discard ewes slaughtered in distinct physiological stages. 21 ewes were used, arranged into the following groups: $E L=$ ewes which remained in lactation for 60 days with their respective lambs and slaughtered one day after weaning; $E W L=$ ewes which remained in lactation for 60 days with their respective lambs for one more period of approximately 30 days without the lambs and slaughtered afterwards; and ENC = ewes which did not give birth during the year. Protein and ashes contents of the sheep meat were close to each other among experimental groups; however, moisture and fat values of the meat were different among them. Significant difference was not found in the sensorial evaluation of the meat proceeding from the distinct groups. It is concluded that the slaughter of discard ewes in different physiological stages promotes alteration in the centesimal composition of the meat concerning its fat and moisture content and there is no difference in the sensorial quality of the meat in the distinct experimental groups.
\end{abstract}

Keywords: sheep, consumer, meat quality

\section{INTRODUÇÃO}

A carne tem grande importância nutricional na alimentação dos seres humanos, sendo considerada alimento altamente nutritivo, fonte de aminoácidos, minerais, água, gordura e vitaminas. A busca por alimentos saudáveis e de qualidade tem sido frequente, e cada vez maior é a preocupação da população em saber a composição nutricional da carne a ser consumida (Pinheiro, 2006). De acordo com Fozooni e

Recebido em 9 de março de 2011

Aceito em 8 de fevereiro de 2012

E-mail: rafaelsbp@bio.feis.unesp.br 
Zamiri (2007), há a preocupação de reduzir os teores de gordura na dieta da maioria das pessoas, e, por este motivo, muitos países estão exigindo menor teor de gordura em cortes cárneos, principalmente por razões relacionadas à saúde humana e à qualidade de vida. Para esses autores, tal fato tem levado à maior investigação de como obter carnes com menores teores de gordura.

Os fatores que levam o consumidor a gostar ou não de uma determinada carne são os aspectos relacionados principalmente à aparência, à maciez, à suculência e ao sabor. Segundo Sañudo (1991), esses aspectos podem variar muito de acordo com idade, sexo, raça e alimentação do animal. $\mathrm{O}$ autor relatou que a qualidade da carne pode ser analisada sob vários pontos de vista: nutricional, higiênico, facilidade de utilização, imagem preestabelecida, apresentação do produto e avaliação sensorial. Conforme Gularte et al. (2000), o grau de satisfação relacionado ao consumo de carnes, de modo geral, depende de respostas psicológicas e sensoriais inerentes a cada indivíduo.

Pesquisas realizadas no Brasil, com o objetivo de avaliar a terminação de vacas de descarte em confinamento ou em pastagem cultivada com ou sem suplementação (Restle et al., 2001; Restle et al., 2002), têm apresentado resultados satisfatórios quanto à melhoria das características qualitativas da carcaça e da carne, quando comparados aos de fêmeas terminadas em sistema extensivo (Perobelli et al., 1994; Perobelli et al., 1995). No entanto, estudos neste sentido com a espécie ovina são raros.

De acordo com Zundt et al. (2003), o teor de proteína na carcaça dos ovinos jovens diminui com o aumento da idade deles, enquanto a quantidade de gordura aumenta. A definição do ponto ideal de abate dos ovinos, em geral, é preconizada pelo peso vivo do animal; entretanto, nem sempre um animal com um determinado peso tem um acabamento desejado de gordura de cobertura e apresenta boa qualidade da carne. Sabe-se que sexo, nutrição (Kozloski et al., 2006), músculo (Zeola et al., 2007), sistema de terminação (Santos et al., 2010), e raça (Cartaxo et al., 2011) influenciam na qualidade da carne, principalmente na oriunda de ovinos jovens. No entanto, não se conhece muito a qualidade da carne de ovinos adultos de descarte, bem como não se sabe a melhor forma de terminar estes animais para o abate e em qual momento (estágio fisiológico) deve-se realizar tal procedimento para que apresentem boa qualidade da carne e esta seja bem aceita pelo consumidor.

Pelo exposto e pela escassez de informações na literatura científica sobre este assunto, o presente trabalho teve como objetivos estudar a composição centesimal do músculo Longissimus lumborum e a aceitação sensorial do músculo Longissimus thoracis, provenientes de ovelhas de descarte da raça Santa Inês, abatidas em diferentes estágios fisiológicos, bem como estimar as possíveis correlações entre a composição centesimal e as características sensoriais da carne.

\section{MATERIAL E MÉTODOS}

Utilizaram-se 21 ovelhas de descarte da raça Santa Inês, após um período de estação de monta, de um rebanho comercial. No início do estudo, os animais apresentaram peso corporal de, aproximadamente, $43 \pm 2,87 \mathrm{~kg}$, com idade média de $72 \pm 11$ meses. Utilizaram-se sete ovelhas por tratamento. As ovelhas foram distribuídas nos seguintes grupos: OL= ovelhas que permaneceram por 60 dias em lactação com respectivas crias e que foram abatidas um dia após o desmame dos cordeiros; OSC = ovelhas que permaneceram por 60 dias em lactação com suas respectivas crias e mais um período aproximado de 30 dias sem os cordeiros e que, posteriormente, foram abatidas; $\mathrm{ONP}=$ ovelhas que permaneceram por 60 dias junto das ovelhas do OL e OSC até o abate e que não pariram durante o ano.

O delineamento experimental utilizado foi o inteiramente ao acaso, com três grupos de animais e sete repetições, para determinar a composição centesimal da carne. Para as análises estatísticas dos dados da avaliação sensorial da carne, foi adotado o delineamento em blocos ao acaso, com três grupos e 42 repetições (provadores).

As ovelhas permaneceram em regime de confinamento em uma instalação coberta com área de solário, alimentação e água à vontade durante todo o período do experimento. Todas as ovelhas foram abatidas no mesmo dia, portanto 
as fêmeas do OSC pariram um mês antes das do OL, e todos os partos foram simples.

A dieta fornecida apresentou relação volumoso:concentrado de 70:30 e foi fornecida em quantidade correspondente a $4 \%$ do peso corporal/dia. O volumoso foi o feno de Tifton 85 , e o concentrado constituído por $69,6 \%$ de grão de milho moído, $24,8 \%$ de farelo de algodão, $0,8 \%$ de calcário calcítico, $0,8 \%$ de fosfato bicálcico e $4 \%$ de suplemento vitamínico e mineral. Os animais receberam duas refeições diárias, às sete e às 16 horas, em cocho de madeira, que permitiu o acesso de todos os animais ao mesmo tempo. Os cordeiros tiveram acesso a comedouro seletivo, onde foi oferecido concentrado à vontade. Todos os animais tiveram acesso a sal comum fornecidos em cocho.

Foram coletadas amostras da dieta - início, meio e final do experimento - fornecida às ovelhas para determinação dos teores de matéria seca, proteína bruta, extrato etéreo, matéria mineral, lignina, fibra em detergente neutro, fibra em detergente ácido, assim como do nitrogênio insolúvel em detergente neutro e do nitrogênio em detergente ácido, conforme descrito na Tab. 1.

Tabela 1. Composições percentual e bromatológica da dieta experimental fornecida às ovelhas (\% MS)

\begin{tabular}{|c|c|}
\hline Composição percentual (\%) & $(\% \mathrm{MS})$ \\
\hline Grão de milho moído & 20,88 \\
\hline Farelo de algodão & 7,44 \\
\hline Calcário calcítico & 0,24 \\
\hline Fosfato bicálcico & 0,24 \\
\hline Suplemento mineral $^{1}$ & 1,20 \\
\hline Feno de Tifton -85 & 70,00 \\
\hline \multicolumn{2}{|l|}{ Composição bromatológica (\%) } \\
\hline Matéria seca & 89,13 \\
\hline Matéria mineral & 4,97 \\
\hline Proteína bruta & 11,81 \\
\hline Extrato etéreo & 2,12 \\
\hline Fibra em detergente neutro & 58,46 \\
\hline Nitrogênio insolúvel em detergente neutro & 0,29 \\
\hline Fibra em detergente ácido & 30,29 \\
\hline Nitrogênio insolúvel em detergente ácido & 0,14 \\
\hline Lignina & 4,08 \\
\hline
\end{tabular}

No manejo pré-abate, as ovelhas permaneceram em jejum de 16 horas de dieta sólida e, em seguida, foram insensibilizadas por eletronarcose, quando então foram seccionadas as veias jugulares e as artérias carótidas para sangria. Após a retirada da pele, a evisceração e a retirada da cabeça e das extremidades dos membros, as carcaças foram transferidas para câmara frigorífica a $5^{\circ} \mathrm{C}$ por 24 horas. Ao final desse período, as carcaças foram divididas longitudinalmente em duas partes, sendo retirados da meia carcaça esquerda os cortes do lombo e das costelas, e destes cortes foi retirado o músculo L. lumborum do corte do lombo, e do corte das costelas o músculo L. thoracis, ambos desprovidos de gordura subcutânea.
As carnes foram congeladas em freezer a $-18^{\circ} \mathrm{C}$, por um período aproximado de quatro meses, e, posteriormente, analisou-se a composição centesimal do músculo $L$. lumborum. Essa análise foi realizada em triplicata, e o músculo $L$. thoracis foi utilizado para a avaliação sensorial.

As análises de umidade, proteína, extrato etéreo e cinzas foram realizadas segundo os métodos recomendados pela AOAC (Association..., 1995).

A análise sensorial da carne foi realizada de acordo com o descrito por Pinheiro (2006), da qual participaram 42 consumidores não treinados, apreciadores de carne ovina. Utilizou- 
se o teste de aceitação sensorial, com escala hedônica de 9 pontos, considerando-se os seguintes atributos: sabor - sensação de gosto e odor liberados pela amostra durante a mastigação -, maciez - percepção da força necessária para obter o cisalhamento da amostra ao morder -, aparência - visualização da aparência do produto. Também se aplicou o teste de preferência - somatória de todas as percepções sensoriais sobre a qualidade da carne. Os 9 pontos da escala variaram de 1 - desgostei muitíssimo - a 9 - gostei muitíssimo.
Para as análises de variância, foi utilizado o procedimento do SAS (Statistical..., 1996). As médias dos grupos foram comparadas pelo teste Tukey a 5\% de probabilidade. Para determinar o coeficiente de correlação entre as variáveis estudadas, fez-se uso da correlação de Pearson, segundo o procedimento CORR do programa SAS (Statistical..., 1996).

\section{RESULTADOS E DISCUSSÃO}

A composição centesimal da carne proveniente de ovelhas de descarte abatidas em distintos estágios fisiológicos encontra-se na Tab. 2.

Tabela 2. Composição centesimal do músculo Longissimus lumborum de ovelhas de descarte abatidas em diferentes estágios fisiológicos

\begin{tabular}{lccccc}
\hline \multirow{2}{*}{ Variável (\%) } & \multicolumn{3}{c}{ Estágio fisiológico } & \multirow{2}{*}{ CV $(\%)$} & \multirow{2}{*}{ Teste F } \\
\cline { 2 - 4 } & OL & OSC & ONP & & \\
\hline Umidade & $75,61 \mathrm{a}$ & $74,63 \mathrm{~b}$ & $74,82 \mathrm{ab}$ & 0,92 & $4,89^{*}$ \\
Proteína & 19,43 & 19,51 & 19,42 & 2,36 & $0,36^{\mathrm{NS}}$ \\
Extrato etéreo & $3,95 \mathrm{~b}$ & $4,81 \mathrm{a}$ & $4,74 \mathrm{a}$ & 10,22 & $7,52^{* *}$ \\
Cinzas & 1,00 & 1,04 & 0,99 & 7,60 & $0,77^{\mathrm{NS}}$ \\
\hline
\end{tabular}

Valores seguidos por letras distintas na mesma linha diferem significativamente entre si pelo teste Tukey a $5 \%$ de probabilidade. $\mathrm{NS}=$ não significativo $(\mathrm{P}>0,05) . *=$ Significativo $(\mathrm{P}<0,05) . * *=$ Significativo $(\mathrm{P}<0,01)$.

A umidade da carne diferiu $(\mathrm{P}<0,05)$ entre os grupos estudados, com a maior porcentagem para a carne das ovelhas abatidas um dia após o desmame dos seus cordeiros em relação à carne das ovelhas do grupo OSC. Quanto ao teor de umidade da carne, o dos animais do grupo ONP foi próximo aos obtidos nos demais grupos experimentais (Tab. 2). Tal resultado pode ser explicado pelo fato de a carne das ovelhas OL ter apresentado menor teor de gordura em relação à carne das ovelhas OSC. Resultados próximos aos deste estudo para o teor de umidade foram registrados por Zapata et al. (2001), que, ao avaliarem borregos Somális Brasileira x Crioula e Santa Inês x Crioula, obtiveram valor de umidade da carne de $76,1 \%$ e $76,2 \%$, respectivamente.

O teor de extrato etéreo do músculo $L$. lumborum diferiu $(\mathrm{P}<0,01)$ entre os grupos experimentais (Tab. 2), com menor valor para o grupo OL em relação aos grupos OSC e ONP, que apresentaram valores de extrato etéreo semelhantes $(\mathrm{P}>0,05)$ entre si. A explicação deste resultado foi em razão do estágio fisiológico das ovelhas OL - lactação -, que é o período de maior exigência nutricional, quando, provavelmente, ocorreu perda de peso corporal e, consequentemente, de tecido muscular e adiposo, em comparação aos animais dos demais grupos desta pesquisa. Entre os componentes da carne, a água é o maior constituinte, e seu teor é inversamente proporcional ao de gordura (Dabés, 2001), como observado neste estudo (Tab. 2 e 4).

Berge et al. (1999) verificaram que ovinos adultos apresentam valores de extrato etéreo no músculo $L$. dorsi de $2,4 \%$ a $3,0 \%$. Os valores de extrato etéreo obtidos na carne ovina por Souza et al. (2002) oscilaram de $1,2 \%$ a $5,2 \%$, explicado pelo fato de os autores terem trabalhado com ovinos abatidos com diferentes pesos $(15,25,35$ e $45 \mathrm{~kg}$ ) e sexos (machos não castrados e fêmeas). Os resultados obtidos neste estudo para o teor de extrato etéreo são mais altos que os registrados por Berge et al. (1999) e menores que os obtidos por Klein Júnior et al. (2006) no músculo L. lumborum de cordeiros. Tal resultado pode ser explicado pelo fato de o teor de extrato etéreo na carne ovina variar muito, principalmente em função do sexo do animal, da raça, da alimentação, do tipo de músculo, do peso de abate e, também, do estágio fisiológico em que o animal se encontra, como pode ser verificado neste estudo. 
Carnes provenientes de animais adultos normalmente são associadas como prejudiciais à saúde humana, por apresentarem alto teor de gordura na sua composição; no entanto, os resultados desta pesquisa evidenciaram que é possível obter carnes com diferentes composições centesimais, sobretudo o teor de gordura, abatendo os animais em diferentes estágios fisiológicos (Tab. 2). Fozooni e Zamiri (2007) relataram que há a necessidade de reduzir o teor de gordura da carne pelo fato de muitos consumidores de diversos países estarem exigindo menores teores de gordura nos alimentos, principalmente por questões relacionadas à qualidade de vida e saúde.

A composição nutricional dos alimentos vem sendo investigada em diversos estudos científicos, especialmente o teor de gordura, pela sua influência na qualidade dos alimentos. Kemp et al. (1981) relataram que os cortes cárneos com maior conteúdo de tecido adiposo, normalmente, são os que apresentam maior suculência na carne e também alteração do sabor. De acordo com Madruga et al. (2005), o sabor e o aroma característicos da carne de cada espécie animal estão relacionados ao teor de gordura no músculo.

No presente estudo, os teores de proteína e de cinzas do músculo $L$. dorsi foram próximos $(\mathrm{P}>0,05)$ entre os grupos experimentais, com valores médios de $19,4 \%$ e $1,01 \%$, respectivamente. Os resultados obtidos por Horcada et al. (1998), Pérez et al. (2002) e Madruga et al. (2005) são próximos aos verificados no presente estudo, para os teores de proteína e de cinzas da carne ovina.

$\mathrm{Na}$ Tab. 3 constam os valores médios dos atributos sensoriais - aparência, sabor, maciez e preferência - da carne de ovelhas abatidas em diferentes estágios fisiológicos.

Tabela 3. Valores médios da aceitação sensorial determinada no músculo Longissimus thoracis de ovelhas de descarte abatidas em diferentes estágios fisiológicos

\begin{tabular}{lccccc}
\hline \multirow{2}{*}{ Atributo } & \multicolumn{3}{c}{ Estágio fisiológico } & \multirow{2}{*}{ CV (\%) } & \multirow{2}{*}{ Teste F } \\
\cline { 2 - 4 } & OL & OSC & ONP & & \\
\hline Aparência & 6,85 & 6,81 & 7,00 & 21,64 & $0,12^{\mathrm{NS}}$ \\
Sabor & 6,70 & 6,63 & 7,44 & 24,50 & $1,90^{\mathrm{NS}}$ \\
Maciez & 6,48 & 6,70 & 7,44 & 24,70 & $2,38^{\mathrm{NS}}$ \\
Preferência & 6,70 & 6,55 & 7,40 & 21,22 & $2,62^{\mathrm{NS}}$ \\
\hline
\end{tabular}

$\mathrm{NS}=$ não significativo $(\mathrm{P}>0,05)$.

Não houve diferença significativa dos atributos sensoriais estudados - aparência, sabor e maciez - entre os grupos experimentais, bem como do teste de preferência aplicado aos diferentes grupos, com valores médios de 6,88, 6,92, 6,87 e 6,88 , respectivamente. A maciez da carne é, provavelmente, a característica mais estudada quando a preocupação é o consumidor (Chambers e Bowers, 1993). A textura da carne pode determinar a qualidade e a aceitabilidade dela pelos consumidores, e a melhor qualidade da carne é, normalmente, expressa em termos de maior maciez e maior suculência (Borges et al., 2006).

Os resultados obtidos no estudo de Madruga et al. (2005) foram confirmados no presente estudo para a aceitação sensorial da carne, isto é, aparência, maciez e sabor da carne ovina foram similares. Segundo os autores, esses valores de aceitação sensorial da carne são considerados como indicadores de boa qualidade da carne ovina de animais jovens. A carne utilizada nesta pesquisa, proveniente de ovelhas adultas de descarte da raça Santa Inês, apresentou características sensoriais adequadas, de acordo com a avaliação sensorial realizada pelos provadores, e semelhantes aos valores relatados por Madruga et al. (2005), isto é, indicaram carne de boa qualidade.

Os coeficientes de correlação entre os componentes químicos da carne de ovelhas de descarte encontram-se na Tab. 4.

Os resultados evidenciaram correlação negativa $(\mathrm{P}<0,05)$ entre o teor de umidade e de gordura da carne ovina (Tab. 4). Segundo Forrest et al. (1979), a umidade na carne é inversamente proporcional à gordura. Também se verificou correlação negativa $(\mathrm{P}<0,05)$ entre os teores de umidade e de proteína da carne, isto é, quanto 
maior a umidade da carne menor será o seu teor de proteína. Não ocorreu correlação $(\mathrm{P}>0,05)$ entre o extrato etéreo e o teor de cinzas da carne.

Os coeficientes de correlação de Pearson entre os atributos sensoriais da carne ovina encontram-se na Tab. 5. Observou-se correlação positiva
$(\mathrm{P}<0,01)$ entre maciez e sabor da carne e também entre os atributos sensoriais estudados - sabor, maciez e aparência - em relação à preferência da carne. Na avaliação sensorial realizada por Silva et al. (2007), a suculência da carne bovina apresentou correlação positiva com maciez.

Tabela 4. Coeficiente de correlação (r) e probabilidade $(P)$ entre os componentes químicos da carne de ovelhas de descarte da raça Santa Inês

\begin{tabular}{lcccc}
\hline Variável & & Umidade & Proteína & Extrato etéreo \\
\hline Proteína & $\mathrm{r}$ & $-0,50$ & & \\
\multirow{2}{*}{ Extrato etéreo } & $\mathrm{P}$ & 0,02 & & \\
& $\mathrm{r}$ & $-0,48$ & $-0,23$ & \\
Cinzas & $\mathrm{P}$ & 0,02 & 0,30 & 0,13 \\
& $\mathrm{r}$ & 0,75 & $-0,51$ & 0,57 \\
\hline
\end{tabular}

Tabela 5. Coeficiente de correlação (r) e probabilidade $(\mathrm{P})$ entre os atributos sensoriais da carne de ovelhas de descarte da raça Santa Inês

\begin{tabular}{lcccc} 
Variável & & Sabor & Maciez & Aparência \\
\hline Maciez & $\mathrm{r}$ & 0,53 & & \\
\multirow{3}{*}{ Aparência } & $\mathrm{P}$ & 0,01 & & \\
& $\mathrm{r}$ & 0,18 & 0,33 & \\
Preferência & $\mathrm{P}$ & 0,42 & 0,13 & 0,56 \\
& $\mathrm{r}$ & 0,67 & 0,69 & 0,01 \\
\hline
\end{tabular}

\section{CONCLUSÕES}

O abate de ovelhas de descarte em diferentes estágios fisiológicos promove alteração na composição centesimal do músculo L. lumborum quanto ao teor de gordura e de umidade. Os atributos avaliados no teste de aceitação sensorial - aparência, sabor e maciez - e a preferência da carne de ovelhas de descarte são semelhantes mesmo quando abatidas em distintos estágios fisiológicos, e são de boa aceitação quanto aos atributos sensoriais por apreciadores de carne ovina.

\section{REFERÊNCIAS}

ASSOCIATION of official analytical chemists (AOAC). Official methods of analyses chemists. $16^{\mathrm{a}}$. edição. Arlington, 1995.

BERGE, P.; SANCHEZ, A.; DRANSFIELD, E. et al. Variations of meat composition and quality in different commercial lamb types. In: INTERNATIONAL CONGRESS OF MEAT SCIENCE AND TECHNOLOGY, 45., 1999, Yokohoma. Anais... Yokohoma: [s.n]. 1999. p.502-503.
BORGES, A.S.; ZAPATA, J.F.F.; GARRUTI, D.S. et al. Medições instrumentais e sensoriais de dureza e suculência na carne caprina. Cienc. Tecnol. Alim., v.26, p.891-896, 2006.

CARTAXO, F.Q.; SOUSA, W.H.; CEZAR, M.F. Características de carcaça determinadas por ultrassonografia em tempo real e pós-abate de cordeiros terminados em confinamento com diferentes níveis de energia na dieta. Rev. Bras. Zootec., v.40, p.160-167, 2011.

CHAMBERS, E.; BOWERS, J.R. Consumer perception of sensory qualities in muscle foods. Food Technol., v.47, p.116-120, 1993.

DABÉS, A. C. Propriedades da carne fresca. Rev. Nacional Carne, v.25, p.32-40, 2001.

FORREST, J.C.; ABERLE, E.D.; HEDRICK, H.B. et al. Fundamentos de ciencia de la carne. Zaragoza: Editorial Acribia, 1979. 364p.

FOZOONI, R.; ZAMIRI, M.J. Relationships between chemical composition of meat from carcass cuts and the whole carcass in Iranian fattailed sheep as affected by breed and feeding level. Iran. J. Vet. Res., v.8, p.304-312, 2007. 
GULARTE, M.A.; TREPTOW, R.O.; POUEY, J.L.F. et al. Idade e sexo na maciez da carne de ovinos da raça Corriedale. Cienc. Rural, v.30, p.485-488, 2000.

HORCADA, A.; BERIAIN, M.J.; PURROY, A. et al. Effect of sex on meat quality of Spanish lamb breeds (Lacha and Rasa Aragonesa). J. Anim. Sci., v.67, p.541-547, 1998.

KEMP, J.D.; MAHYUDDIN, M.; ELY, D.G. et al. Effect of feeding systems, slaughter weight and sex on organoleptic properties and fatty acid composition of lamb. J. Anim. Sci., v.51, p.321-330, 1981.

KLEIN JÚNIOR, M.H.; SIQUEIRA, E.R.; ROÇA, R.O. Qualidade da carne de cordeiros castrados e nãocastrados confinados sob dois fotoperíodos. Rev. Bras. Zootec., v.35, p.1872-1879, 2006.

KOZLOSKI, G.V.; TREVISAN, L.M.; BONNECARRÈRE, L.M. et al. Níveis de fibra em detergente neutro na dieta de cordeiros: consumo, digestibilidade e fermentação ruminal. Arq. Bras. Med. Vet. Zootec., v.58, p.893-900, 2006.

MADRUGA, M.S.; SOUSA, W.H.; ROSALES, M.D. et al. Qualidade das carne de cordeiros Santa Inês terminados com diferentes dietas. Rev. Bras. Zootec., v.34, p.309-315, 2005.

PÉREZ, P.; MAINO, M.; TOMIC, G. et al. Carcass characteristics and meat quality of Suffolk Down suckling lambs. Small Rum. Res., v.44, p.233-240, 2002.

PEROBELLI, Z.V.; MULLER, L.; RESTLE, J. Estudo da qualidade das carcaças e da carne de vacas de descarte de dois grupos genéticos. Cienc. Rural, v.24, p.613-616, 1994.

PEROBELLI, Z.V.; RESTLE, J.; MÜLLER, L. Estudo das carcaças de vacas de descarte das raças Charolês e Nelore. Pesq. Agropec. Bras., v.30, p.409412, 1995.

PINHEIRO, R.S.B. Aspectos quantitativos da carcaça e qualitativos da carne de ovinos de diferentes categorias. 2006, 105f. Dissertação (Mestrado em Zootecnia), Universidade Estadual Paulista, Faculdade de Ciências Agrárias e Veterinárias, Botucatu, SP.

RESTLE, J.; VAZ, F.N.; ROSO, C. et al. Desempenho e características da carcaça de vacas de diferentes grupos genéticos em pastagem cultivada com suplementação energética. Rev. Bras. Zootec., v.30, p.1813-1823, 2001.
RESTLE, J.; FATURI, C.; BERNARDES, R.A.C. et al. Efeito do grupo genético $\mathrm{e}$ da heterose na composição física e nas características qualitativas da carcaça e da carne de vacas de descarte terminadas em confinamento. Rev. Bras. Zootec., v.31, p.1378-1387, 2002.

SAÑUDO, C. La calidad orgnoléptica de la carne com especial referencia a la especie ovina. Factores que la determinan, metodos de medida y causas de variacion. 1991. 225f. Thesis - Facultad de Veterinaria, Zaragoza, Espanha.

SANTOS, J.R.S.; PEREIRA FILHO, J.M.; SILVA, A.M.A. et al. Efeito da suplementação na composição física e centesimal da paleta, do costilhar e do pescoço de cordeiros Santa Inês terminados em pastejo. Arq. Bras. Med. Vet. Zootec., v.62, p.906-913, 2010.

SILVA, M.L.; CONTRERAS-CASTILLO, C.J.; ORTEGA, E.M.M. Efeito do cozimento na qualidade do músculo Semitendinosus. Cien. Tecnol. Alim., v.27, p.787-792, 2007.

SOUZA, X.R.; PEREZ, J.R.O.; BRESSAN, M.C. et al. Características da carcaça e da carne de novilhos e de vacas de descarte Hereford, terminadas em confinamento. Rev. Bras. Zootec., v.31, p.1501-1510. 2002.

STATISTICAL ANALYSIS SYSTEM Institute. SAS. User's Guide to Statistics. Version 6.12. Cary, USA: North Caroline State University, 1996.

ZAPATA, J.F.F.; NOGUEIRA, C.M.; SEABRA, L.M.A.J. et al. Composição centesimal e lipídica da carne de ovinos do nordeste brasileiro. Cienc. Rural, v.31, p.691-695, 2001.

ZEOLA, N.M.B.L.; SOUZA, P.A.; SOUZA, H.B.A. et al. Cor, capacidade de retenção de água e maciez da carne de cordeiro maturada e injetada com cloreto de cálcio. Arq. Bras. Med. Vet. Zootec., v.59, p.10581066, 2007.

ZUNDT, M.; MACEDO, F.A.F.; MARTINS, E.N. et al. Características de carcaça de cordeiros terminados em confinamento, com dietas contendo diferentes níveis proteicos. Cienc. Rural, v.33, p.565-571, 2003. 